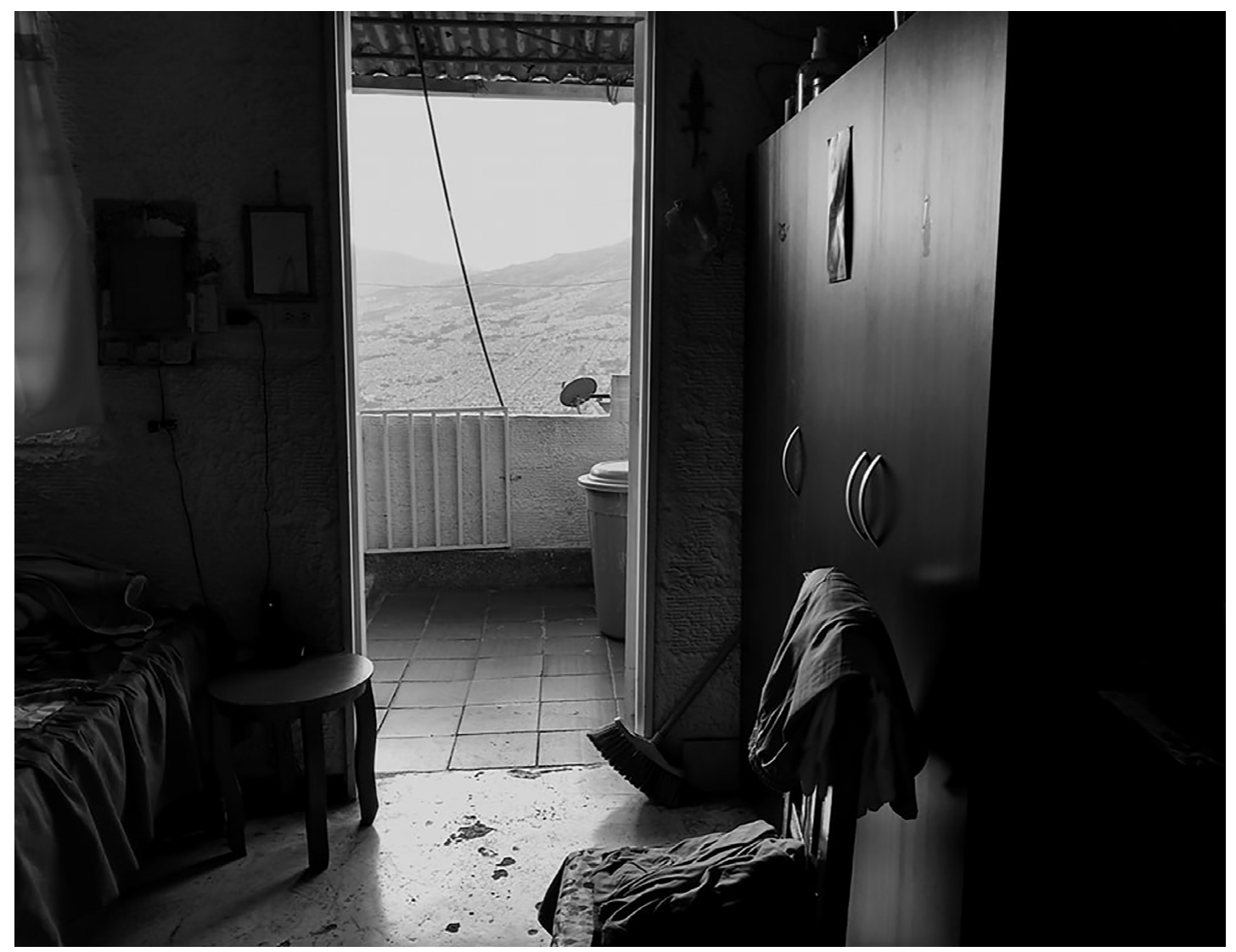

Artista invitada

Any Lorena Blandón Higuita

Un día en la vida de mi abuela (2)

Fotografía digital blanco y negro

2018

Cortesía Revista Ojo de Pez 


\title{
Realidad social y narconovelas. Perspectivas de la violencia en jóvenes de la Comuna 13 de Medellín*
}

\author{
Andrés Fernando Orozco Macías (Colombia)**
}

\section{Resumen}

Esta investigación busca analizar la perspectiva de 48 jóvenes de la Comuna 13 de la ciudad de Medellín sobre la violencia a partir del ámbito social en el que viven y las narconovelas que visualizan en televisión. Se desarrolló la discusión sobre cuál es el papel de la televisión en la formación social de los jóvenes. Para el análisis de perspectivas se optó por el modelo cualitativo de grupos focales, el cual permitió el contraste y debate sobre estos ámbitos de análisis. Se cuestionó el panorama que pretende sostener que la televisión influye sobre los comportamientos y se vinculó a la relación histórica y social de la violencia que produce el microtráfico, las bandas organizadas y la justicia por mano propia, estableciendo correlaciones con la realidad social y no una influencia para actuar como tal.

\section{[204] Palabras clave}

Comunicación Política; Representación Social; Representación Mediática; Televisión; Narcoviolencia; Jóvenes.

Fecha de recepción: junio de 2020 - Fecha de aprobación: noviembre de 2020

\section{Cómo citar este artículo}

Orozco Macías, Andrés Fernando. (2021). Realidad social y narconovelas. Perspectivas de la violencia en jóvenes de la Comuna 13 de Medellín. Estudios Políticos (Universidad de Antioquia), 60, pp. 204-223. DOI: 10.17533/udea.espo. n60a09

\footnotetext{
* Artículo resultado de la investigación de la línea de Tecnología y Sociedad del grupo Historia, Trabajo, Sociedad y Cultura, Universidad Nacional de Colombia sede Medellín. https://scienti.minciencias.gov. co/gruplac/jsp/visualiza/visualizagr.jsp?nro=00000000003866

** Historiador. Magíster en Estudios Políticos. Investigador de la Universidad Nacional de Colombia sede Medellín. Correo electrónico: andresorozco08@gmail.com - Orcid: 0000-0001-6778-1153 Google Scholar: https://scholar.google.com/citations?hl=es\&user=SLAWYzkAAAAJ
} 


\title{
Social Reality and Narco-Soap Operas. Perspectives of Violence in Young People in Comuna 13 of Medellin
}

\begin{abstract}
This research seeks to analyze the perspective of 48 young people from Comuna 13 of the city of Medellín on violence based on the social environment in which they live and the narco-soap operas they see on television. The discussion on what is the role of television in the social formation of young people was developed. For the analysis of perspectives, the qualitative model of focus groups was chosen, which allowed the contrast and debate on these areas of analysis. The panorama that pretends to maintain that television influences behavior was questioned and was linked to the historical and social relationship of violence produced by microtrafficking, organized gangs and justice by own hand, establishing correlations with social reality and not a influence to act as such.
\end{abstract}

\section{Keywords}

Political Communication; Social Representation; Media Representation; Television; Drug Violence; Youth. 


\section{Introducción}

La Comuna 13 de la ciudad de Medellín es un objeto de investigación donde se refleja una parte de la violencia y el conflicto armado en Colombia. Allí han confluido todo tipo de violencias: de las milicias urbanas, de las guerrillas, del Cártel de Medellín, de los paramilitares y de las diferentes organizaciones criminales que operan en la zona encargadas de la extorsión y el microtráfico. De esta manera, es importante reconocer que la televisión colombiana y extranjera no han desaprovechado estos momentos trágicos en la historia de Colombia para la realización de narconovelas que rememoran los acontecimientos sucedidos durante el periodo de los cárteles, en producciones como Los Tres Caines, la cual representa acontecimientos claves en el surgimiento y desarrollo del paramilitarismo.

El desarrollo de esta investigación se abocó a conocer si la televisión y las narconovelas generan algún tipo de influencia en los jóvenes habitantes de las zonas afectadas por la violencia de la Comuna 13, y si conllevan a que ingresen a ese mundo del narco y microtráfico, muy relacionado con la realidad social en la que viven.

[206] Lo que la investigación trató de demostrar es que la televisión, aunque convincente en determinados aspectos publicitarios, está desligada de la realidad social de muchos de estos jóvenes. Con ello solo consiguen que realicen correlaciones entre el mundo social en el que viven y algunas características de estas narconovelas, es decir, la televisión no los lleva a actuar como las narconovelas, sino que asimilan realidades vigentes, tanto en el relato televisivo como en la realidad social en la que viven.

Factores como la ausencia del Estado en aspectos de seguridad, la dignificación urbana de la zona, entre otros factores, se convierten en aspectos trascendentales para que los jóvenes investigados comprendieran determinadas estructuras de la realidad históricas de la ciudad de Medellín y la permanencia de las raíces del conflicto armado en Colombia.

\section{Televisión y narcoviolencia, ¿espacio de influencia o de manipulación?}

El debate social y político de la televisión como espacio de influencia en niños y adolescentes aún está vigente. En esta investigación se plantea que el problema no es la influencia, sino la manipulación de los contenidos que 
se presentan allí a partir de las narcoseries y, a su vez, cómo esas imágenes manipuladas son contrastadas con su realidad, lo cual los lleva a desear vidas de consumo y propiedades. Esta manipulación nace:

Cuando muestra algo distinto de lo que tendría que mostrar si hiciera lo que se supone que se ha de hacer; es decir, informar, y también cuando muestra lo que debe, pero de tal forma que hace que pase inadvertido o que parezca insignificante, o lo elabora de tal modo que toma un sentido que no corresponde en absoluto a la realidad (Bourdieu, 2013, p. 25).

Pierre Bourdieu (2013) se refiere al tema de la manipulación con el concepto de ocultar mostrando. Es un modelo comunicativo y político que se refiere solo a determinados aspectos de la realidad social de los individuos, por ejemplo, cuando los telenoticieros hablan del robo, pero no de las causas estructurales de este para favorecer cierta agenda política, por el contrario, el debate de los medios de comunicación como influencia pretenden enunciar que los individuos actúan directamente como lo indica la televisión.

En lo concerniente al estudio de las consecuencias para los televidentes ya existen resultados precisos desde la década de 1960, esto indican que las imágenes de violencia aumentan la predisposición a la violencia y por consiguiente contribuyen al aumento de los actos violentos [...].

Tras finalizar la escuela primaria un niño ha observado en la pantalla un promedio de 8000 asesinatos y 100000 actos violentos, luego del doceavo [sic] año los números ascienden aproximadamente 32000 asesinatos y 40000 intentos de asesinato en un $73 \%$ de los casos los autores no sufren castigos, en un 58\% las imágenes de violencia no muestran sus consecuencias, en muy pocos casos $4 \%$ se muestran formas no violentas de superar el conflicto (Buddemeier, 2016, pp. 9-11).

Este tipo de perspectivas no tienen en cuenta factores políticos, económicos y sociales que puedan llevar a este tipo de problemáticas. Aspectos como el incremento poblacional, el desempleo y la consolidación de modelos políticos que generan el incremento de la precarización de las clases sociales más bajas no están en ese modelo explicativo de la televisión como influenciadora.

En el ámbito de análisis de la televisión como influencia, algunas perspectivas más radicales vinculan las actuaciones de los sujetos a partir de 
la identidad que les proporcionan los programas televisivos, es decir, muchos jóvenes que han crecido frente a la pantalla vinculan rasgos de su personalidad e identidad con lo que le han trasmitido y, en consecuencia, actúan de modo similar. Estos mismos teóricos consideran que desde que fue inventada la televisión «viene acompañando y dando soporte al proceso de la formación, y coincidiendo en que los medios, más que moldear y crear identidades, ofrecen patrones de comportamiento y de relaciones sociales mediante los que trasmiten valores» (Montero, 2006, p. 50), dando herramientas y bases sociales para comportarse de modo violento, desconociendo otros aspectos de su realidad social (García, 2008; Buddemeier, 2016; Villasmil, 2015).

En casos puntuales de investigaciones sobre la influencia de figuras de violencia social y política, como es el caso de las narconovelas, autoras como Adriana Jastrzębska (2017) destacan que el capitalismo exacerbado y las libertades ilimitadas en el consumo de drogas, alcohol y prostitución llevan a los televidentes a desear determinadas formas de vida allí presentadas y a aprobar desde su condición — quizás de precariedad y escasez- las acciones violentas de estas figuras que representan al narco como «superador» de la pobreza desde la ilegalidad a «falta de oportunidades».

[208] Ese tipo de aspectos permiten comprender que no se refiere directamente a que las narconovelas televisivas influencien sobre el sujeto, sino que evidencia su realidad frente a la pantalla, sus carencias y necesidades. Por lo que este tipo de producciones se hacen atractivas, porque relatan audiovisualmente al televidente un acontecimiento histórico de problemáticas que aún persisten en su realidad.

En ese mismo juego de modelos de vida acorde con la ideología capitalista también se esclarece una especie de negocio de prototipos de vida y de personalidades promovidos por las industrias audiovisuales, los cuales reviven los estilos de vida de los narcotraficantes, proponiendo lo ilícito como un modelo rentable, con la misma idea de vivir una vida de consumos ilimitados, lujos y propiedades, mientras exponen la pobreza anterior como espacio superado de modo ilegal (Palaversich, 2015; Escobar, 2018).

La manipulación nace cuando esas excentricidades que se presentan carecen de estructura narrativa frente a los referentes políticos y sociales, ocultando la raíz de un Estado ausente en la prevención de los focos de formación de la violencia, el narcotráfico y la delincuencia; cuando solo se 
relata centralmente la biografía de un narco y su estilo de vida, pero no las estructuras socioestatales que llevaron a su producción en la realidad histórica.

La figura de Pablo Escobar en narconovelas como El Patrón del Mal es considerada en algunas investigaciones como una especie de populismo mediático, donde la figura de Escobar resalta una confrontación de clases sociales; es usado por las oligarquías como enemigo del pueblo, al igual que es usado por algunos sectores de las clases bajas como un ejemplo de justicia y heroicidad:

Lo primero es entender que el «gran» criminal es aquel que confronta al Estado y su monopolio de la violencia, despertando en su acción desafiante, la admiración del pueblo [...]. En este sentido, podemos decir que esta estrategia y punto de vista narrativo establece características que estructuran a Escobar y su causa como las buenas y al mismo tiempo se lleva a rechazar el otro grupo, el del Estado y la ley, al presentarlo de manera antagónica y opuesto a la causa popular (Castrillón, 2017, pp. 68-70).

El autor reconoce un nivel de manipulación mediática que permite interpretar y re-interpretar la figura de Pablo Escobar de acuerdo a los intereses de la industria mediática, incluso de las agendas políticas, pretendiendo construir una figura dual que sea atractiva y repudiada al mismo tiempo, la creación de un héroe y antihéroe para sostener una doble moral, en la medida que se consume como figura televisiva (Rocha, 2016). Es en ese juego donde las emociones del televidente se ven en una encrucijada, al evidenciar cómo se humaniza la figura de Pablo Escobar en medio del debate moral de sus acciones:

La excitación emocional se asocia con la intención de humanizar a Escobar y el intento por construir su imagen de hombre familiar, de esposo protector que siente, que llora y que sufre, con valores emocionales y, como menciona Ferrez (1996), se juega a la construcción de la identificación, de la cercanía, del atractivo y en la excitación sensorial produce en el espectador por el modelo observado (Fernández y Giraldo, 2018, p. 168).

La relación con las emociones que se presentan audiovisualmente y el modo como se afrontan en medio del rechazo y las dificultades permiten la producción del héroe. A pesar de su fortaleza dramatizada o vivenciada en la realidad social, también son familiares y sensibles a las circunstancias, que 
tienen una historia y unas razones para actuar que no desconocen y justifican. Eric Hobsbawm (2011) reconoce este factor cuando habla de los bandidos y señala que «su papel consiste [en ser un] paladín, corregir los abusos, aporta [a] la justicia y la igualdad social» (p. 56).

Hobsbawm (2011) desarrolla de manera trascendental el concepto de bandido justo y su relación social, su politización y, sobre todo, su aparición en las sociedades como una forma alternativa para ejercer una justicia no monopolizada, es decir, no estatal. Las relaciones conceptuales que desarrolla el autor son claves para observar cómo desde la percepción de los jóvenes y su realidad social se comprende el concepto de justicia en actores no legales y, sobre todo, cómo a partir de un relato televisivo se forman la idea de un narcotraficante como Pablo Escobar, a quien no conocieron, y les permitió desarrollar un debate entre las ficciones virtuales y la realidad de esas problemáticas que aún persisten.

\section{Marco metodológico}

El sector de la Comuna 13 se consideró de vital importancia para el desarrollo de esta investigación, pues su proceso histórico de violencia en

[210] los últimos treinta años marcó fuertes cambios social y urbano en la ciudad de Medellín, en especial, por la Operación Orión en octubre de 2002 y las actuales bandas criminales que operan en la zona.

Ese antecedente de violencia desarrollado por diferentes estructuras militares y organizaciones criminales permitió la búsqueda de percepciones de la violencia en la realidad social de la Comuna 13, a partir de los enfrentamientos violentos y de la televisión como anunciadora de factores reales, pero sin estructura histórica como el narcotráfico (microtráfico), la ausencia estatal en el ámbito de la seguridad y defensa de los derechos humanos, la actuación de las bandas criminales e individuos no estatales como gestores de un «orden social» a partir del terror y la violencia, evidenciando la realidad social a partir de las narcoseries.

Para el desarrollo de una investigación en el modelo de perspectivas se optó por los grupos focales como espacio para el cruce y contrastes de opiniones sobre temáticas. Se eligieron 48 jóvenes entre los 13 y 16 años. Se consideró que estas edades eran pertinentes en procesos de indagación de percepción pues inicia la etapa del adolecer en búsqueda de patrones de identidad juvenil. Estos 48 jóvenes compusieron grupos de 3 integrantes para 
un total de 16 grupos. Los voluntarios para el proceso de investigación eran estudiantes de colegios oficiales de la Comuna 13.

La investigación se realizó en 2018 y 2019 en las etapas expuestas en el cuadro 1:

Cuadro 1. Ejes clave de la estructura metodológica.

\begin{tabular}{|c|c|c|c|c|}
\hline $\begin{array}{l}\text { Inicio y } \\
\text { discusión }\end{array}$ & $\begin{array}{c}\text { DOFA y } \\
\text { encuesta } 1\end{array}$ & $\begin{array}{c}\text { Contextualización } \\
\text { y conceptos }\end{array}$ & Encuesta 2 y 3 & $\begin{array}{c}\text { Debate y } \\
\text { conclusiones }\end{array}$ \\
\hline $\begin{array}{l}\text { Se abrió el } \\
\text { debate sobre la } \\
\text { percepción y } \\
\text { la explicación } \\
\text { de la } \\
\text { intencionalidad } \\
\text { de la } \\
\text { investigación. } \\
\text { Los jóvenes } \\
\text { expusieron } \\
\text { sus primeras } \\
\text { impresiones } \\
\text { sobre el tema. }\end{array}$ & \begin{tabular}{|l|} 
Junto con \\
un mapa \\
parlante, los \\
grupos focales \\
discutieron y \\
reconocieron \\
las principales \\
problemáticas de \\
su comunidad. \\
La encuesta 1 fue \\
de conocimiento \\
general sobre \\
percepción de \\
violencia en las \\
narconovelas \\
y la realidad \\
social.
\end{tabular} & $\begin{array}{l}\text { Los jóvenes } \\
\text { conocieron } \\
\text { los conceptos } \\
\text { desde los que } \\
\text { se abordaría la } \\
\text { investigación, } \\
\text { los autores y la } \\
\text { contextualización } \\
\text { histórica de la } \\
\text { Comuna } 13 \\
\text { desde el ámbito } \\
\text { académico. }\end{array}$ & $\begin{array}{l}\text { Los jóvenes } \\
\text { identificaron } \\
\text { la presencia } \\
\text { del Estado en } \\
\text { la zona en } \\
\text { contraste con las } \\
\text { organizaciones } \\
\text { criminales que } \\
\text { allí operan, } \\
\text { realizando un } \\
\text { comparativo con } \\
\text { lo presentado en } \\
\text { las narconovelas. }\end{array}$ & $\begin{array}{l}\text { En mesa } \\
\text { de debate, } \\
\text { los grupos } \\
\text { explicaron más } \\
\text { ampliamente } \\
\text { sus respuestas, } \\
\text { contrastando } \\
\text { con los } \\
\text { argumentos } \\
\text { de los demás } \\
\text { grupos. }\end{array}$ \\
\hline
\end{tabular}

Fuente: elaboración propia.

El cuadro 1 contextualiza cinco ejes claves de la estructura metodológica de la investigación: el componente de discusión como clave para un primer reconocimiento diagnóstico de perspectivas; en un segundo momento, la DOFA, como fortalecimiento conceptual de estas perspectivas que permitieron la contextualización conceptual y encontrar una base para comprender las respuestas de las encuestas y los resultados.

De acuerdo con lo anterior, los jóvenes lograron consolidar un proceso compuesto por dos momentos: la primera parte fue de percepción y descripción a partir de las vivencias en su realidad social y televisiva; la segunda, a partir del desarrollo de las encuestas 3 y 4, se ampliaron a una perspectiva más crítica de las dos realidades propuestas en esta investigación. 


\section{La violencia y los bandidos en las narconovelas y la realidad social}

\subsection{Contexto}

En 1991 varias de las organizaciones armadas de Medellín — como las Milicias Populares del Pueblo y para el Pueblo (MPPP), el Ejército Popular de Liberación (EPL) y las Milicias Metropolitanas de Medellín—-decidieron firmar una desmovilización y un acuerdo de paz con el gobierno de César Gaviria. Para ese momento, el paramilitarismo iniciaba la fase más importante de su avanzada por el territorio colombiano. Durante el acuerdo con las milicias, algunas se vieron rezagadas en el proceso de desmovilización, entre estas las que operaban en la Comuna 13.

Para la década de 1991 en adelante las CAP (Comandos Armados del Pueblo) y el frente Carlos Alirio Buitrago del ELN consolidaron su poder en toda la Comuna 13, ejercieron el control militar de la zona, después, «Hacia los años 1997-1998 esta situación cambió. Los CAP y el ELN se trenzaron en disputas por el control de territorios en las que los CAP obtuvieron la mayor ventaja y lograron ampliar su dominio territorial en varios sectores estratégicos de la Comuna 13» $(\mathrm{CNMH}$, 2017, p. 146).

Sin duda, la retaliación entre los CAP y el ELN llevó a desmanes y crímenes contra la población civil, siendo esta la principal justificación, junto con la ausencia del Estado para que un grupo de paramilitares ingresara al barrio El Salado el 4 de julio de 2002 y asesinaran a tres pobladores, desplazaran a sesenta familias compuestas por cuatrocientas personas, a lo que se sumó la incineración de sus casas (Rendón, 2017). Ese fue el punto de partida para la avanzada paramilitar, junto con la Operación Orión el 16 de octubre 2002, que con la posterior imagen del periodista Jesús Abad Colorado publicada por la revista Semana (2015, agosto 15) evidenció la relación entre la fuerza pública y el paramilitarismo en el desarrollo y despliegue de la avanzada.

El desarrollo de la violencia en la Comuna 13 de Medellín es de vital importancia para comprender las ideas que los jóvenes y los pobladores tienen de su comunidad. Durante la investigación, cuando se les pidió a los 48 jóvenes individualmente que relataran un acontecimiento trascendental de su comunidad, 95,75\% se refirió a la Operación Orión. En consonancia, los relatos de la comunidad sobre un acontecimiento histórico se nutren de la vigencia de una violencia configurada ya no en modelos ideológicos, como 
lo pretendieron las milicias de extrema izquierda o los paramilitares de la extrema derecha, sino de variados combos armados en disputa territorial por el control de la extorsión y el microtráfico.

Aunque muchos jóvenes no están relacionados con el microtráfico, nutren el orden lógico de su ámbito social con las narconovelas, que muestran una parte de la realidad colombiana del narcotráfico y la violencia que mantiene vigencia en el mundo social. Es este aspecto lo que la hace atractiva como entretenimiento para muchos televidentes.

\section{2 «Telerrealidad» y violencia}

Markus Gabriel (2019a) realiza una crítica a los modelos constructivistas de la realidad social, señalando que solo son procesos interpretativos de acuerdo a las conveniencias de poderes discursivos y disciplinares, por ejemplo: atribuir la pobreza de algunos sectores a la falta de deseo para trabajar no explica la naturaleza política y social de la pobreza, es decir, solo realizan construcciones sociales de algunos factores de acuerdo a los resultados que busca un discurso disciplinar que favorece una mirada ideológica o una agenda política.

¿Qué es la realidad? La Realidad consiste en la circunstancia de que hay objetos y hechos sobre los que podemos estar equivocados porque no se explicitan debido a que tengamos ciertas opiniones acerca de ellos. Lo real corrige nuestras opiniones. Debido a la realidad de nuestros pensamientos podemos estar equivocados, pero también podemos estar en lo cierto (p. 304).

Gabriel (2019b) reconoce que tanto el mundo social de los sujetos como sus pensamientos y opiniones, hacen parte de la realidad; igualmente, la virtualidad y la televisión pertenecen al mundo de lo real. Lo que debate el autor es que estos factores coinciden con la realidad de los acontecimientos, que muchas veces son símiles. Por ejemplo, en nuestra opinión se puede despreciar la violencia, pero nuestras opiniones no modifican las razones de su existencia en un ámbito determinado y por eso el poder de los discursos lo manipula o lo apropia a su conveniencia.

Respecto a la realidad de la violencia en los dos ámbitos propuestos a investigar, se les preguntó a los dieciséis grupos: ¿dónde encuentran más violencia: en la realidad social en la que vives o en la televisión? El 62\% de los grupos consideraron que presenciaban más violencia en la televisión, 
mientras 38\% de los integrantes señaló que la realidad social de su sector; $62 \%$ concluyó que las narconovelas eran el principal aspecto televisivo de generación de violencia mediática, pero reconocieron que es una forma de evidenciar un acontecimiento histórico de la violencia en Colombia. Aunque el 38\% no es una cifra muy representativa, esos grupos encontraron en su barrio más violencia a través de los combos armados e incluso del abuso de algunos miembros de las fuerzas militares en el sector.

Lo que se demostró allí es que en ambos ámbitos se reconoció la existencia de la violencia como factor trascendental de los dos espacios, en las narconovelas como área de sucesos de los cárteles que operaron en Colombia y en la realidad social como secuela de la violencia de esos cárteles que persiste a causa de problemáticas que el Estado colombiano no logra resolver y que los jóvenes identificaron en el desarrollo de sus DOFA:

a) La vigencia del microtráfico como forma de supervivencia económica:

Entre los grupos de edad, el mayor consumo de sustancias ilícitas en el último año se observa en el grupo de 18 a 24 años con 13,7\%, superior en 5 puntos porcentuales al valor nacional para este grupo de edad $(8,7 \%)$. En segundo lugar se encuentra el grupo de 25 a 34 años con $7,2 \%$ superior en 2,9 puntos porcentuales al valor nacional de este grupo de edad $(4,3 \%)$ [...]. El consumo reciente en el departamento se ubica en el $1,6 \%$, presentando un porcentaje superior más de dos veces al valor nacional (ODC, 2017, pp. 148-150).

b) Ausencia del Estado a través de procesos de dignificación de vivienda: en 2019, alrededor de 55000 viviendas se derrumbaron porque infringieron el Plan de Ordenamiento Territorial (POT) (Redacción Nacional, 2019, abril 30). A este flagelo se suman desplazados que buscan en las zonas periféricas de la ciudad espacios para construir con materiales rústicos, sumándose a ello la mala estructura de las calles y la planificación urbana que dificulta el acceso.

c) Ausencia del Estado a través de una fuerza pública con regulación de protocolos de intervención que no atente contra la población civil: según informe de Human Rights Watch (2020, marzo 10) para Colombia, «El Ministerio de Defensa también indicó el 3 de marzo que la Policía Nacional había iniciado 44 investigaciones disciplinarias en relación con las protestas, incluidas 27 por "abuso de autoridad", 6 por "agresión física", 2 por "privación ilegal de la libertad" y 2 por "homicidio"»». 
d) Falta de control del Estado frente al monopolio de las armas de fuego: esa política del Estado ausente es la misma que propició el surgimiento de fuerzas ilegales que asumieron el control territorial de algunas zonas de Colombia. Ante la vulneración de derechos entre civiles y, en ocasiones, frente a los abusos del Estado, nacen las autodefensas campesinas y posteriores guerrillas; ante los abusos de estas surgen las organizaciones paramilitares y posteriormente las bandas organizadas, ocupando territorios. Todas coinciden en un mismo proceso de financiación y mantenimiento: control territorial, extorsión y narcotráfico.

Los jóvenes son receptores de esos cuatro momentos, tanto en el ámbito televisivo como en su realidad social. Los cuatro son predecibles y están en los libretos de las narconovelas y en la realidad social. Lo novedoso es que la televisión se permitió convertir esos factores en espectáculo de una violencia positivizada (Han, 2017) que tiene como referente la realidad histórico-social.

Una característica esencial de lo anterior lo identificó Guy Debord (2015) al reconocer el espectáculo como una relación social de las personas mediatizada por imágenes: «el espectáculo es la sociedad misma». Siempre motivada, positiva y atractiva, que cumple a cabalidad con los prototipos que ella expone a la sociedad, no como influencia, sino como forma de demostrar eficiencia en la sociedad misma. La telerrealidad solo existe en la medida en que la sociedad puede verse allí positivizada (Han, 2017): «El espectáculo se presenta como una enorme positividad, indiscutible e inaccesible. No dice más que esto: "Lo que aparece es bueno, lo bueno es lo que aparece"» (Debord, 2015, p. 41).

La pantalla televisiva tiene la ventaja de hacer aparecer lo que se desea, se presenta la realidad pasada o presente en forma de entretenimiento, permite generar a la audiencia una mirada re-interpretada del pasado donde positiviza y humaniza a los villanos, no muestra en sí misma las estructuras históricas de la violencia, pero las hace atractivas a través de sus personajes. Esa relación entre el proceso del espectáculo televisivo y la estandarización de emociones que muestran a los villanos como seres humanos sensibles y familiares, justifican las acciones violentas a través de una interiorización de la violencia (Han, 2017) que relaciona las razones y las acciones de estos sujetos presentados en las narconovelas. 


\subsection{Justicia y autoridad territorial}

Byung-Chul Han (2017) cuestionó el panorama del panóptico disciplinario de Michel Foucault. Todo ese exterior de violencia se interiorizó en el sujeto del rendimiento y de la eterna positivización, en la misma medida que se desarrolló una autoagresividad del sujeto, explotador y explotado en un mismo cuerpo. La perspectiva de Han (2016) ya no solo recurre a la visibilidad de la violencia social, si no a su invisibilidad que se interioriza y, sobre todo, permite la normalización de muchos actos violentos del espacio exterior. Por ello la fuerza represiva del Estado es repudiada como forma de orden y control social, porque la fuerza de modelos psicopolíticos es más efectivo en su proceso de interiorización, aceptación y normalización:

La técnica de poder del régimen neoliberal adopta una forma sutil. No se apodera directamente del individuo. Por el contrario, se ocupa de que el individuo actúe de tal modo que reproduzca por sí mismo el entramado de dominación que es interpretado por él como libertad. La propia optimización y el sometimiento, la libertad y la explotación coinciden aquí plenamente. A Foucault se le oculta totalmente la técnica de poder que genera la convergencia entre libertad y explotación en la forma de autoexplotación (p. 46).

Por ello, los prototipos de violencia expuestos en las series televisivas son formas de consumo de diferentes tipos de violencia interiorizada y aceptada como parte de diversión, pero al tiempo como búsqueda de coincidencia con una realidad vigente.

Santiago Giraldo (2018) expone cómo Pablo Escobar revive la violencia justificada que se refleja a partir de los cuatro aspectos ya mencionados y resaltados por los investigados en la DOFA.

En las series de narcos los protagonistas siempre son los personajes principales que despliegan una violencia de espectáculo para el mantenimiento de la teleaudiencia, sorteando las dificultades violentas que les propone el mismo desarrollo de los acontecimientos, que hacen justicia por sus propias manos $y$, en especial, una marcada ausencia escenográfica de las fuerzas del Estado.

Para que los jóvenes durante esta investigación reconocieran esas cuatro realidades expuestas en la DOFA, se usó el concepto de bandido justo 
de Hobsbawm (2011), donde se expusieron característica como: «Corregidor de los abusos, roba a los ricos para dar a los pobres, no mata nunca si no es en defensa propia o en justa venganza, es enemigo del poder establecido» (p. 59). Aunque estos conceptos se ubican en una realidad histórica diferente a la que se indagó, pareciera que el accionar de muchos de estos sujetos estuviera relacionado con ese imaginario colectivo de las narconovelas y de la realidad social en la que operan integrantes de estas agrupaciones.

El análisis de las características del bandido justo se desarrolló en dos momentos: En el primero se propuso indagar si en el caso de Pablo Escobar se trataba de un bandido justo o de un criminal, a partir de la idea que les generó estas narcoseries a los investigados; en el segundo momento se analizó cómo los jóvenes perciben otros modelos de autoridad civil más allá de los impuestos por el Estado, a partir del modelo de bandido justo.

Gráfica 1. Contraste entre las respuesta negativas y positivas de los estudiantes encuestados.

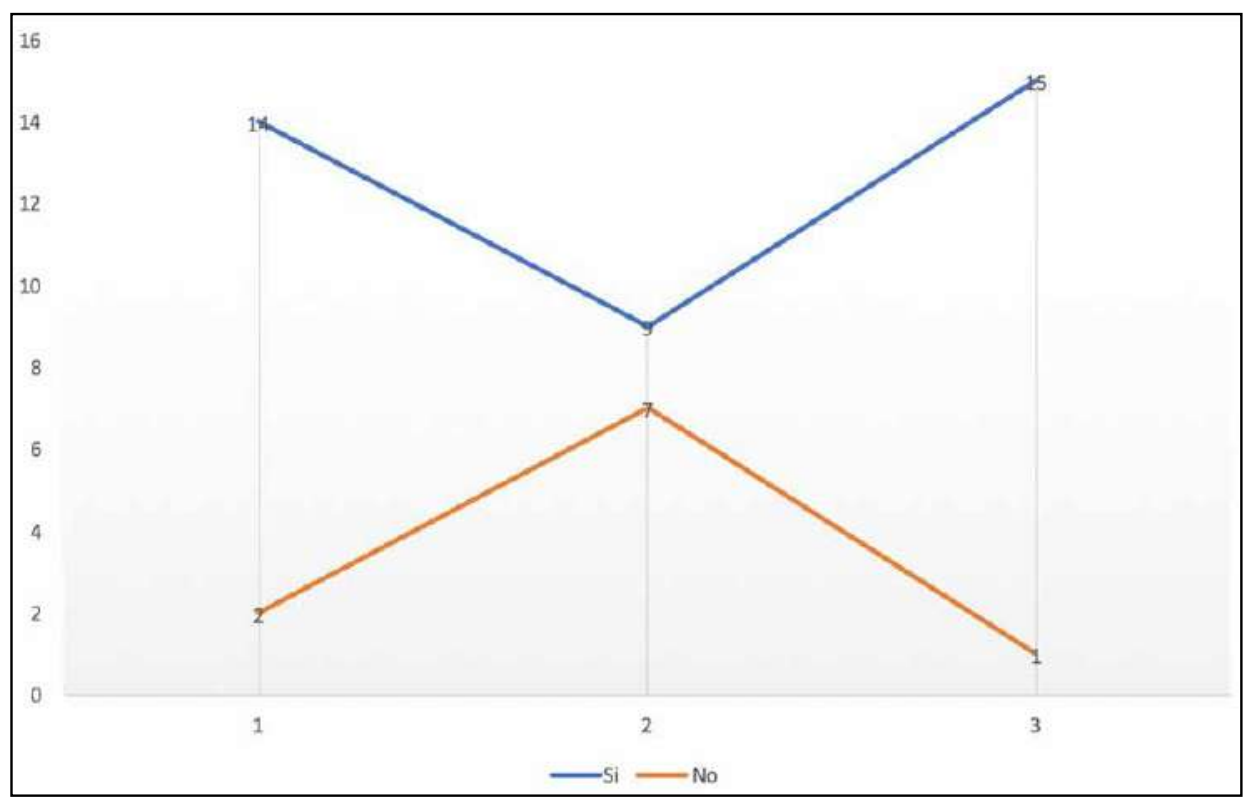

Fuente: elaboración propia. ${ }^{*}$ La línea horizontal representa las preguntas enunciadas y la línea vertical los grupos.

En la tercera encuesta de la investigación se realizaron tres preguntas a los dieciséis grupos: 
- ¿Han observado series televisivas en las que se presencie violencia y narcotráfico?

— ¿Los personajes que lo protagonizan parecen ser justos?

- ¿Crees que las autoridades del Estado ayudan al desarrollo de la justicia en esos escenarios de las narconovelas?

Para la primera pregunta, 14 grupos, equivalentes a 42 jóvenes $(87,5 \%)$ sí observaron alguna vez series televisivas relacionadas con narcotráfico y violencia, teniendo la posibilidad de establecer modelos comparativos entre lo que presentan los medios y su realidad social, es decir, aunque presenciaron violencia en su ámbito relacionada con el microtráfico, siguen considerando que la televisión desarrolla más violencia.

Para la segunda pregunta, 9 de los grupos, equivalentes al 56,25\%, consideraron que la actuación de los personajes de las narconovelas en medios televisivos es de seres «justos», es decir, que perciben en sujetos armados que no representan al Estado un posible corregidor de abusos que actúan bajo «razones justificadas» que los llevan a actuar de esa manera (Hobsbawm, 2011).

Para la tercera pregunta, 93,75\% de los jóvenes investigados consideraron que las narconovelas y el Estado a través de sus múltiples aparatos militares no contribuyen al desarrollo de la justicia en las tramas televisivas, es decir, esto juega en un doble sentido: primero, se identifica que aunque las narconovelas tratan de ser un relato histórico de una realidad social, los organismos de seguridad no son fundamentales en el desarrollo de la trama; y en segundo lugar, que aunque no todos los personajes protagonistas son buenos ni justos, el Estado no ha tenido ningún protagonismo «mediático ni real en representar y defender la justicia social».

De acuerdo con la percepción de la justicia en las narconovelas, en la segunda y última parte se indagó un análisis comparativo de la autoridad como fuente representativa de la justicia, en este caso, los protagonistas de las narconovelas frente a la presencia de las autoridades en la Comuna 13, donde viven todos los jóvenes investigados. Se contrapuso a las organizaciones al margen de la ley que operan en bandas criminales, a las autoridades militares del Estado, en relación con la presencia territorial frente a la televisiva. 
Realidad social y narconovelas. Perspectivas de la violencia en jóvenes de la Comuna 13...

En esta última encuesta se indagó la pregunta: ¿quiénes ejercen más autoridad y control territorial, tanto en las narconovelas como en la realidad social que habitas? En este punto se les dejó como antecedente a los investigados que la autoridad se representaba como aquellos que imparten el orden social en nombre del Estado, sin embargo, las respuestas fueron variadas.

Gráfica 2. Presencia de las autoridades militares del Estado frente a la presencia de organizaciones ilegales en lo territorial y televisivo.

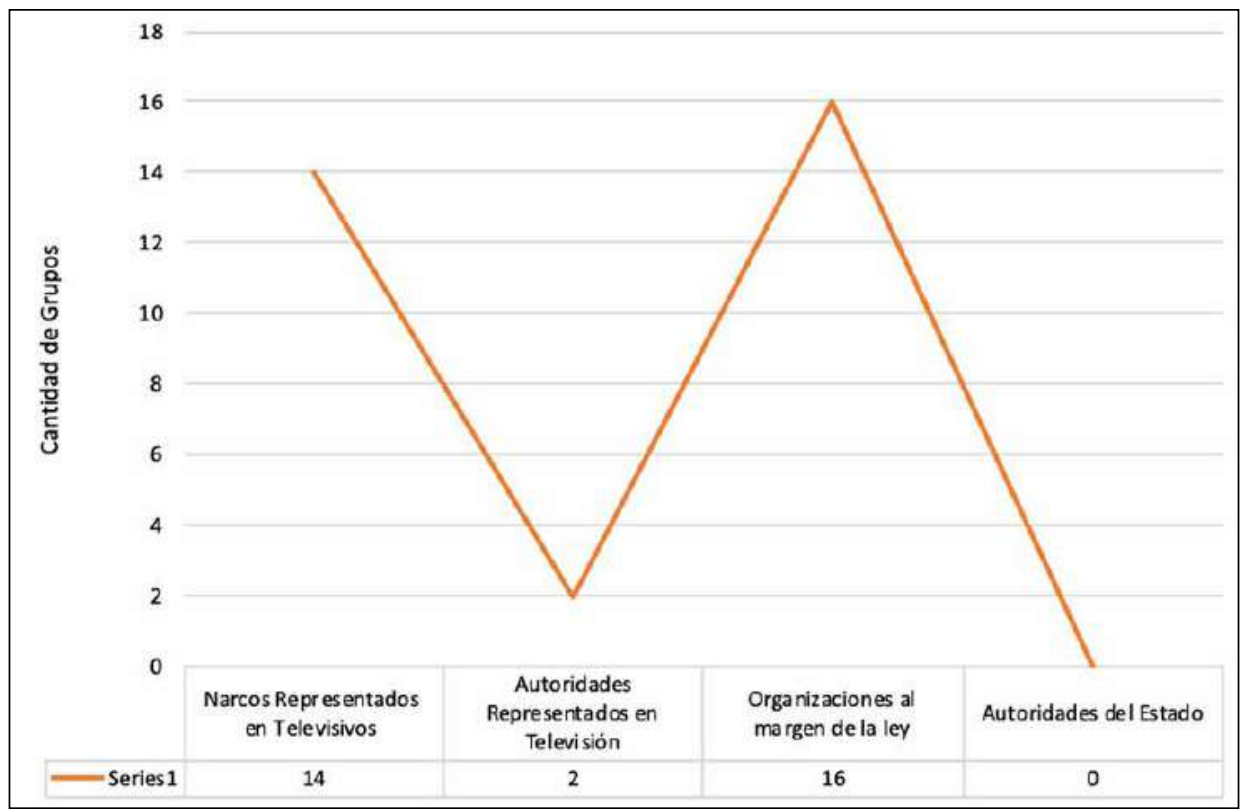

Fuente: elaboración propia.

En referencia a las narconovelas, catorce de los grupos investigados consideraron que los protagonistas de los narcos en televisión demuestran más autoridad, caracterizados por el control de armas, dominación de algunos sectores sociales, «compra de autoridades y representantes de la política». En torno a la realidad social de la Comuna 13, aceptan que, aunque la presencia de la policía existe, no ejercen un modelo de autoridad como lo hacen algunas las organizaciones ilegales o bandas criminales que operan en la zona a través del microtráfico y la extorsión, con un control efectivo de armas que 
atemoriza a comerciantes y transportadores como principales generadores de ingresos. A esto es importante agregar que los jóvenes mencionaron que «a pesar de ser personas violentas [...] ayudan a muchas personas y actúan casi siempre como protectores de las familias y la comunidad» (Grupo Focal 3, comunicación personal, 8 de octubre, 2018), por ello, el siguiente porcentaje fue altamente significativo en lo mencionado anteriormente.

Respecto al desarrollo de los relatos, 95,75\% consideraron que cuando se presentan inconvenientes entre los vecinos las personas acuden a los cabecillas e integrantes de estas organizaciones para que medien las problemáticas y den una especie de veredicto frente a inconvenientes comunes entre vecinos; asimismo, aunque denotan la presencia de la policía en cada esquina, en muchas ocasiones no responden al llamado inmediato cuando son requeridos.

Antecedentes como los anteriores han dado espacio a que esa ausencia estatal en muchas ocasiones permita la ocupación por parte de líderes de organizaciones ilegales y criminales que comienzan con el negocio del microtráfico y la extorsión, pero terminan ejecutando tareas de inquisidores comunitarios, pues «no se trata tanto de hombres que eliminen

[220] Ios abusos, como de vengadores, de brazos ejecutores; su atractivo no es el de agentes de justicia, sino el de unos hombres que muestran que incluso los pobres y los débiles pueden ser terribles» (Hobsbawm, 2011, p. 76. Énfasis añadido).

Entre muchas de las consideraciones de los grupos focales, una de ellas se destacó —entre otras muy similares- por reconocer en los bandidos justos que operaban en esta zona que «muchos de ellos les quitan a los ricos para ayudar a los pobres e incluso defender los derechos humanos de los ciudadanos» (Grupo Focal 1, comunicación personal, 8 de octubre, 2018). Estas ficciones no se asumen como un derrotero unificado de la televisión, sino que se busca en su reducida realidad modos de comprender el entramado social en el que viven.

Los jóvenes no asumen las narconovelas o programas televisivos como influencia, sino como forma de crear correlaciones en el modo como muchas personas superan condiciones de pobreza a partir de la ilegalidad y la violencia, dimensionando razones que justifican las acciones violentas de 
los narcos a partir de los modelos biográficos con alto contenido emocional que proponen estas. Son dos realidades similares que se retroalimentan y se atraen como forma de entretenimiento.

\section{Conclusión}

Reconocer cuál es el papel de la actual televisión resulta clave para comprender las relaciones que los televidentes tienen con ella, y a partir de allí, vislumbrar cómo contextualizan los contenidos con su realidad. Se debatió la tradicional idea que pretende encerrar a la televisión en el marco de influencia, pero más allá de esta idea se contextualizó el espacio televisivo como una oportunidad de manipulación de la realidad histórica y social.

Las narconovelas fueron el escenario para debatir este proceso, comprendiendo que, aunque los libretos no son fieles exponentes de la realidad histórica del narcotráfico en Colombia, permiten a las personas realizar correlaciones con la realidad social en la que viven. En el desarrollo de las encuestas, los jóvenes dimensionaron en qué ámbitos de esas dos realidades encontraron más violencia específica. Evidentemente, la televisión se llevó el principal espacio, pero compartiendo algunas características con la realidad social de los participantes de la investigación.

En las encuestas 1 y 2 , donde estuvo la DOFA, se encontraron aspectos fundamentales como la permanencia del microtráfico como forma de supervivencia económica de algunas personas, pero a esto se sumaron factores tan significativos como la estructura urbanística de la zona, la dignificación de las viviendas y la necesidad de una presencia de las fuerzas del Estado en la protección de los derechos civiles de los habitantes de la Comuna 13.

Los aspectos destacados anteriormente permitieron comprender que las narconovelas cumplen con aspectos similares a los identificados en la DOFA realizada por los jóvenes investigados, denotaron las mismas características violentas y ausentistas del Estado en ambos espacios; sumado a ello, identificaron que otras organizaciones e individuos diferente de las fuerzas del Estado asumen roles de justicieros, infundiendo terror armado entre bandas por el control definitivo de estos espacios. 


\section{Referencias bibliográficas}

1. Bourdieu, Pierre. (2013). Sobre la televisión. Barcelona: Anagrama.

2. Buddemeier, Heinz. (2016). Medios de comunicación y violencia. Buenos Aires: Antroposofica.

3. Castrillón, Edwin. (2017). Imagen e imaginario de Pablo Escobar en Escobar, El Patrón del Mal: Realidad y ficción sobre el narcotráfico en Colombia. (Tesis inédita de maestría). Universidade Federal da Integração Latino-Americana, Foz do Iguaçu.

4. Centro Nacional de Memoria Histórica (CNMH). (2017). Medellín: Memoria de una guerra urbana. Bogotá, D. C.: CNMH.

5. Debord, Guy. (2015). La sociedad del espectáculo. Valencia: Pre-textos.

6. Escobar, Stephany. (2018). La narcotelenovela. Negocio de estereotipos. (Tesis inédita de grado). Universidad Santo Tomas, Bogotá, D. C.

7. Fernández-Rovira, Cristina y Giraldo Luque, Santiago. (2018). Narcos o la caricatura narcótica de una realidad de terror. En: Giraldo Luque, Santiago (ed.). ¿Por qué amamos a Pablo Escobar? Cómo Netflix revivió al narcotraficante más famoso del mundo (pp. 161-184). Barcelona: UOC.

8. García, Carmen. (2008). Televisión, violencia e infancia. Madrid: Gedisa.

9. Giraldo Luque, Santiago (ed.). (2018). ¿Por qué amamos a Pablo Escobar? Cómo Netflix revivió al narcotraficante más famoso del mundo. Madrid: UOC.

10. Han, Chul-Byung. (2016). Psicopolítica. Barcelona: Herder.

11. Han, Chul-Byung. (2017). Tipología de la violencia. Barcelona: Herder.

12. Hobsbawm, Eric. (2011). Bandidos. Barcelona: Planeta.

13. Human Rights Watch. (2020, marzo 10). Colombia: abusos policiales en el contexto de manifestaciones multitudinarias. https://www.hrw.org/es/ news/2020/03/10/colombia-abusos-policiales-en-el-contexto-de-manifestacionesmultitudinarias

14. Jastrzębska, Adriana. (2017). Los héroes del mundo degradado: subjetividades endriagas en la narconóvela. Itinerarios, 1 (26), pp. 59-73.

15. Markus, Gabriel. (2019a). El sentido del pensamiento. Barcelona: Pasado \& Presente.

16. Markus, Gabriel. (2019b). ¿Por qué el mundo no existe? Barcelona: Pasado \& Presente.

17. Montero, Yolanda. (2006). Televisión, valores y adolescencia. Madrid: Gedisa.

18. Observatorio de Drogas de Colombia (ODC). (2017). Caracterización regional de la problemática asociada a las drogas ilícitas en el departamento de Antioquia. Bogotá, D. C.: Ministerio de Justicia y UNODC.

19. Palaversich, Diana. (2015). La seducción de las mafias: la figura del narcotraficante en la narcotelenovela colombiana. Hispanófila, 173, pp. 349-364. https://doi.org/10.1353/hsf.2015.0017 
20. Redacción Nacional. (2019, abril 30). Cerca de 55.000 casas en Medellín están en riesgo de derrumbarse. El Espectador. https://www.elespectador.com/ noticias/nacional/cerca-de-55000-casas-en-medellin-estan-en-riesgo-de-derrumbarse/

21. Rendón, Yoni. (2017). Comuna 13 de Medellín. Medellín: Pulso \& Letra.

22. Rocha, Simone. (2016). De heróis e anti-heróis: escolhas estilísticas e construções de significado na narcotelenovela colombiana Escobar, El Patrón del Mal. Lumina, 10 (3), pp. 1-19. https://doi.org/10.34019/1981-4070.2016.v10.21347

23. Semana. (2015, agosto 15). La foto que destapó los desmanes de la operación Orión. https://www.semana.com/nacion/articulo/la-foto-que-dejo-al-descubierto-losdesmanes-de-la-operacion-orion/438656-3/

24. Villasmil, Liseth. (2015). Narconovelas: retratos de la ambigüedad en la construcción de valores sociales. Ontosemiótica, 2 (4), pp. 61-74. 